\title{
Correlation between the cystathionine-r-lyase (CES) and the severity of peptic ulcer disease
}

\author{
Xiong Chen ${ }^{1}$, Ying-Chun Wan ${ }^{1}$, Tao Guo ${ }^{2}$, Can-Xia Xu${ }^{1, *}$, Fen Wang ${ }^{1}$
}

1.Department of Gastroenterology,The Third Xiangya Hospital,Changsha 410013, Central South University, China.

2.Department of Gastroenterology,The Second Xiangya Hospital,Changsha 410013, Central South University, China.

\begin{abstract}
Background:The infection of Helicobacter pylori (H. pylori) is one of the most important causes of gastric ulcer disease. The role of hydrogen sulfide $\left(\mathrm{H}_{2} \mathrm{~S}\right)$ production in $\mathrm{H}$. pylori-induced gastric ulcer disease.

Aim:The expression of cystathionine- $\gamma$-lyase (CSE) was determined, and correlated with the severity of gastric ulcer disease.

Methods: One hundred and eight patients were selected based on the determination of gastric ulcer and the infection of Helicobacter pylori ( $H$. pylor), including 36 normal control, 36 patients with H. Pylori-negative gastric ulcer, and 36 patients with H. Pylori-positive gastric ulcer. RT-PCR determination was performed to determine the expression of CSE, NF- $x \mathrm{~B}$ and IL-8.

Results:The expression of CSE, NF- $x$ B and IL-8 was higher in the gastric ulcer group than control group $(\mathrm{p}<0.05)$. Compared with the H.pylori-negative gastric ulcer, the expression of CSE, NF- $x \mathrm{~B}$ and IL-8 was higher than H.pylori-positive gastric ulcer group $(\mathrm{p}<0.05)$. For H.pylori-negative gastric ulcer group, the expression of CSE positively correlated with the expression of NF- $\varkappa \mathrm{B}(\mathrm{r}=0.98, \mathrm{p}<0.05)$ and IL-8 $(\mathrm{r}=0.95, \mathrm{p}<0.05)$. For H.pylori-positive gastric ulcer group, the expression of CSE also positively correlated with the expression of NF- $x \mathrm{~B}(\mathrm{r}=0.99, \mathrm{p}<0.05)$ and IL-8 $(\mathrm{r}=0.85, \mathrm{p}<0.05)$.

Conclusion: The expression of CSE was positively correlated with the severity of gastric ulcer.

Keywords: Helicobacter pylori, gastric ulcer, hydrogen sulfide $\left(\mathrm{H}_{2} \mathrm{~S}\right)$, cystathionine- $\gamma$-lyase (CSE)

African Health Sciences 2014;14(1): 189-194 http://dx.doi.org/10.4314/ahs.v14i1.29
\end{abstract}

\section{Introduction}

Many factors contributed to the pathogenesis of peptic ulcer disease, including the utilization of NASIDs and smoking. The infection of Helicobacter pylori (H. pylori) is one of the most important causes of peptic ulcer disease. Helicobacter pylori infects the gastric mucosa and induces chronic active inflammation which affects on gastric acid secretion in a variable and complex manner ${ }^{1}$. During this process, some cytokines (IL-1, IL-6, and IL-8) and chemokines were significantly increased, and nuclear factor kappa B (NF- $x \mathrm{~B})$ was activated ${ }^{2-5}$.

Hydrogen sulfide $\left(\mathrm{H}_{2} \mathrm{~S}\right)$ is intimately connected with the gastrointestinal system, and $\mathrm{H}_{2} \mathrm{~S}$ has been regarded as a product of digestive processes ${ }^{6} . \mathrm{H}_{2} \mathrm{~S}$ has been demonstrated to be an important gaseous signal molecule playing a key role in intestinal inflammation, gastrointestinal motility, secretion

\section{Corresponding author:}

Can-Xia Xu

Department of Gastroenterology

The Third Xiangya Hospital,Changsha 410013,

Central South University, China

E-mail: xucanxia123456@163.com and nociception ${ }^{7} \cdot \mathrm{H}_{2} \mathrm{~S}$ was produced through the biotransformation process of L-cysteine catalyzed by multiple enzymes, including cystathionine- $\beta$-synthase (CBS), cystathionine- $\gamma$-lyase (CSE), and L-cysteine transferase.

CSE is the main enzyme involved in the production of $\mathrm{H}_{2} \mathrm{~S}$ in gastric mucosa. To date, the expression of CSE in H.pylori-induced gastric ulcer remains unclear. Additionally, whether the CSE expression is a key factor for gastric ulcer also needs to be clarified. Therefore, the expression of CSE in H.pylori-induced gastric ulcer was investigated. Furthermore, the correlation study was performed between CSE expression and the expression of $\mathrm{NF}-x \mathrm{~B}$ and IL-8, indicating the important role of CSE expression in H.pylori-induced gastric ulcer.

\section{Materials and Methods \\ Patients}

Patients were selected from the patients with epigastric discomfort admitted into the third xiangya hospital of Central South University between April and December in 2011. Gastric ulcer was diagnosed through gastroscopy and pathological biopsy, and the infection of H.pylori was determined using rapid urase test (RUT), ${ }^{14} \mathrm{C}$ urea breath 
test $\left({ }^{14} \mathrm{C}-\mathrm{UBT}\right)$, pathological examination, and H.pylori culture. The patients with more than two positive items were regarded to be infected by H.pylori, and the patients with all the items negative were considered to not be infected with H.pylori. The patients with gastric cancer or other benign or malignant tumors, and the heat, liver and kidney failure were excluded from the present study.
Based on this standard, there are 36 normal, 36 patients with gastric ulcer but without the infection of H.pylori, and 36 patients with gastric ulcer but with the infection of H.pylori. The detailed information was listed in Table 1 , including gender, age, duration, the size and number of gastric ulcer, and pathological location.

Table 1 General clinical data of research object

\begin{tabular}{llll}
\hline Clinical characteristics & Normal control (n=36) & $\begin{array}{l}\text { H.pylori negative } \\
(\mathrm{n}=36)\end{array}$ & $\begin{array}{l}\text { groups } \\
(\mathrm{n}=36)\end{array}$ \\
$\begin{array}{lll}\text { Gender (male/female) } \\
\text { Age (year) }\end{array}$ & $20 / 16$ & $49 / 17$ & $22 / 14$ \\
Duration (year) & $46.3 \pm 10.4$ & $6.5 \pm 12.4$ & $50.2 \pm 11.5$ \\
Size (cm) & $6.5 \pm 1.2$ & $0.4 \pm 0.2$ & $7.1 \pm 2.1$ \\
Number & None & $2.3 \pm 1.2$ & $0.5 \pm 0.3$ \\
Location(gastric an- & None & $19 / 10 / 7$ & $3.0 \pm 1.4$ \\
trum/fundus of stom- & & & $21 / 9 / 6$ \\
ach/gastric body) & & & \\
\hline
\end{tabular}

Compared with each groups $(p>0.05$.

\section{Experimental materials}

During gastroscopy examination, 5-7 gastric mucosa tissues were taken. Among them, one was used for rapid urase test (RUT), 2-4 tissues were used for pathological examination, one was used for the culture of H.pylori, and one was used for RT-PCR.

\section{RT-PCR determination}

The RT-PCR assay of CSE, NF- $x$ B, and IL-8 expression was performed as previously described ${ }^{8}$. Total RNA was extracted using TRIzol reagent (invitrogen, USA) according to the manufacturer's instructions. The RNA yield and purity were assessed by spectrophotometric analysis. Total RNA (500 ng) from each sample was subjected to reverse transcription with randomnonamer, dNTP and AMV reverse transcriptase in a $10 \mu \mathrm{L}$ reaction mixture. The PCR of cDNA was carried out using Takara Ex Taq Hotstart polymerase, dNTPs and the related primers. After denaturation for $3 \mathrm{~min}$ at $94^{\circ} \mathrm{C}$, the total amount of reaction products was amplified for 30 cycles for all these genes using the following situation: $94^{\circ} \mathrm{C}, 30 \mathrm{~s} ; 58^{\circ} \mathrm{C}, 30 \mathrm{~s} ; 72^{\circ} \mathrm{C}, 120 \mathrm{~s}$ on the TAKARA PCR Thermal Cycler.

\section{Data analysis and statistics}

The results were expressed as mean \pm standard deviation (SD). Statistical differences were evaluated using the two-tailed Student's t-test and considered signifi cant at the ${ }^{*} \mathrm{p}<0.05,{ }^{*} \mathrm{p}<0.01$ level.

\section{Results}

As shown in Fig. 1, the quality of RNA was good, as described by the clear bands of 28S, 18 S and 5S RNA. 
Fig. 1 Electrophoresis of RNA isolated from positive control (1), H.pylori-negative gastric ulcer (2), and H.pyloripositive gastric ulcer (3). 28S RNA, 18S RNA, and 5S RNA was shown in Figure.

A

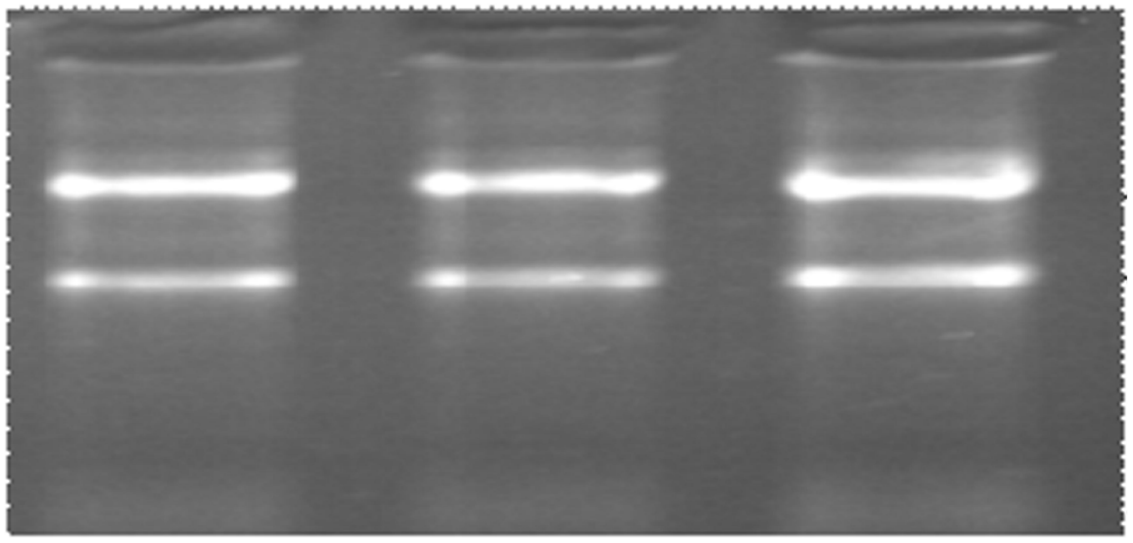

Fig. 1

Additionally, the values of A260/280 and A260/ the expression of CSE, NF- $x$ B and IL-8 was higher in A230 were between 1.9 and 2.0. As shown in Fig. 2, gastric ulcer group than control group ( $<<0.05)$.

Fig. 2 The expression of CSE, NF-xB and IL-8 in normal control, H.pylori-negative gastric ulcer, and H.pyloripositive gastric ulcer group. The data were given as mean+S.D..*p $<0.05$, compared with normal control(\# $\mathrm{p}<0.05$ vs H.pylori-negative gastric ulcer.)

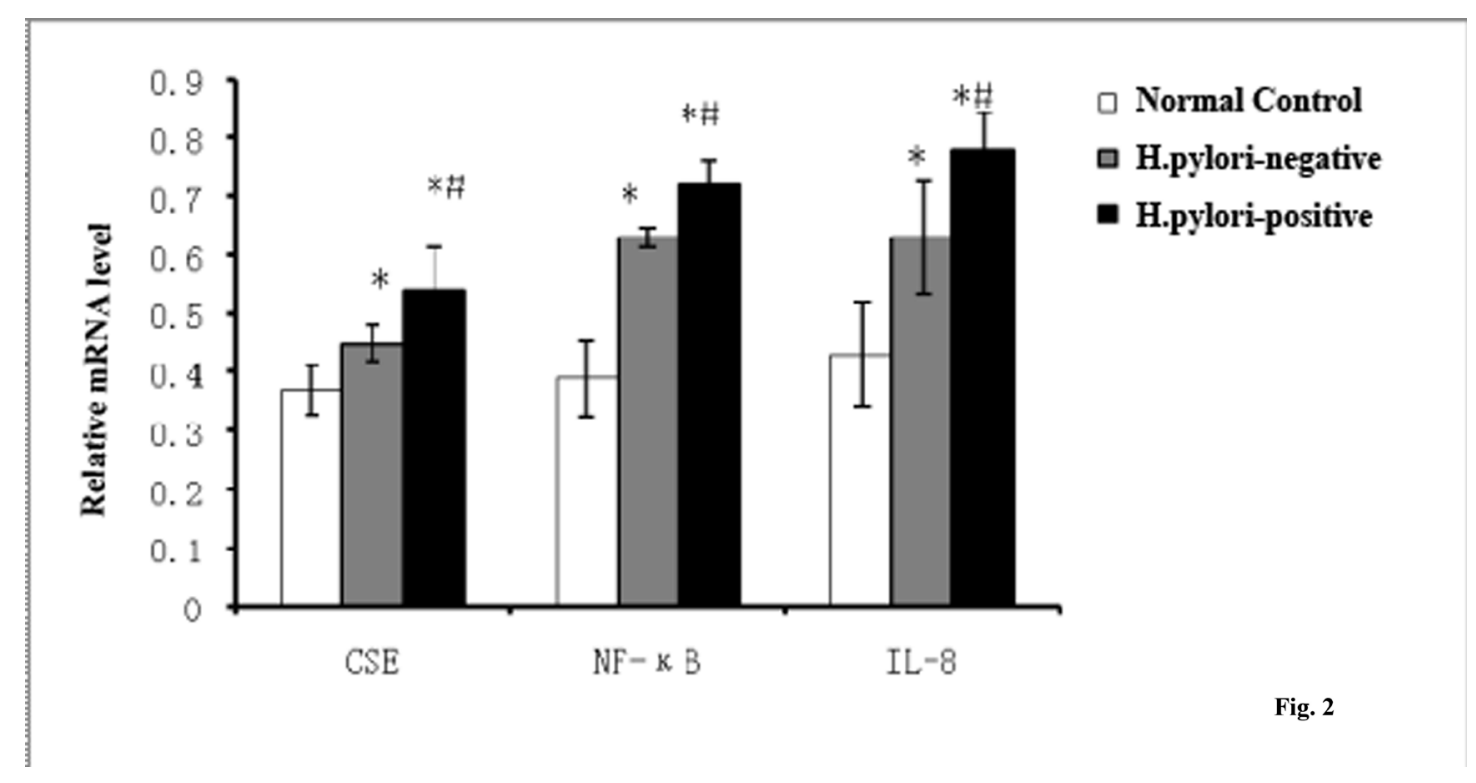

Compared with the H.pylori-negative gastric ulcer, the expression of CSE, NF- $x \mathrm{~B}$ and IL- 8 was higher than H.pylori-positive gastric ulcer group $(\mathrm{p}<0.05)$. In normal group, the expression of CSE did not show correlation with the expression of NF- $x \mathrm{~B}$ and IL-8 ( $>0.05$, data not shown). For H.pylori-negative gastric ulcer group, the expression of CSE positively correlated with the expression of $\mathrm{NF}-x \mathrm{~B}(\mathrm{r}=0.98, \mathrm{p}<0.05)$ and IL-8 $(\mathrm{r}=0.95, \mathrm{p}<0.05)$ (Fig. 3). 
Fig. 3 The correlation between the expression of CSE and the expression of NF- $x \mathrm{~B}$ (A) and IL-8 (B) in H.pylorinegative gastric ulcer group.

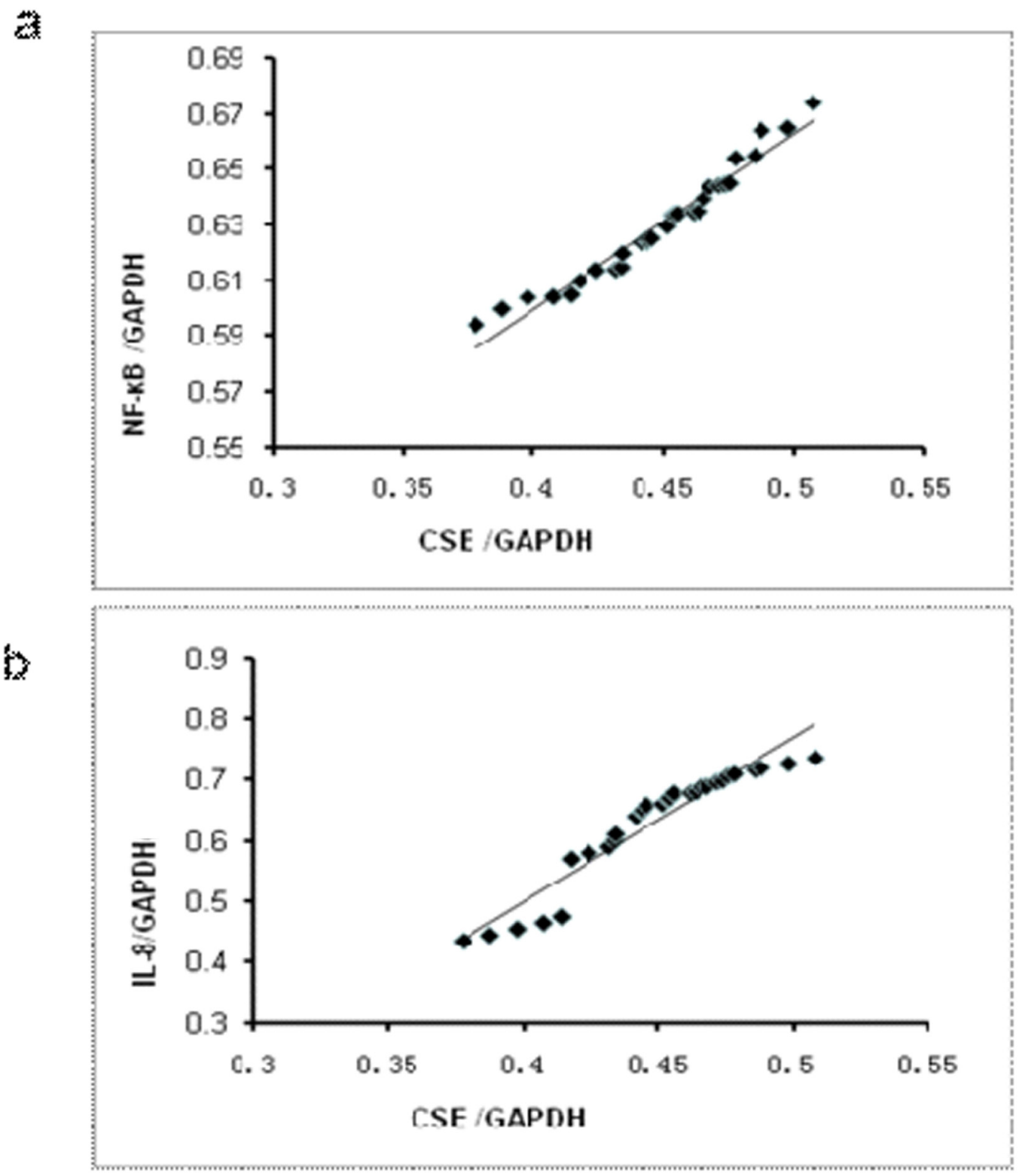

Fig. 3

For H.pylori-positive gastric ulcer group, the expression of CSE also positively correlated with the expression of NF- $x \mathrm{~B}(\mathrm{r}=0.99, \mathrm{p}<0.05)$ and IL-8 $(\mathrm{r}=0.85, \mathrm{p}<0.05)$ (Fig. 4). 
Fig. 4 The correlation between the expression of CSE and the expression of NF- $x \mathrm{~B}$ (A) and IL-8 (B) in H.pyloripositive gastric ulcer group.

a

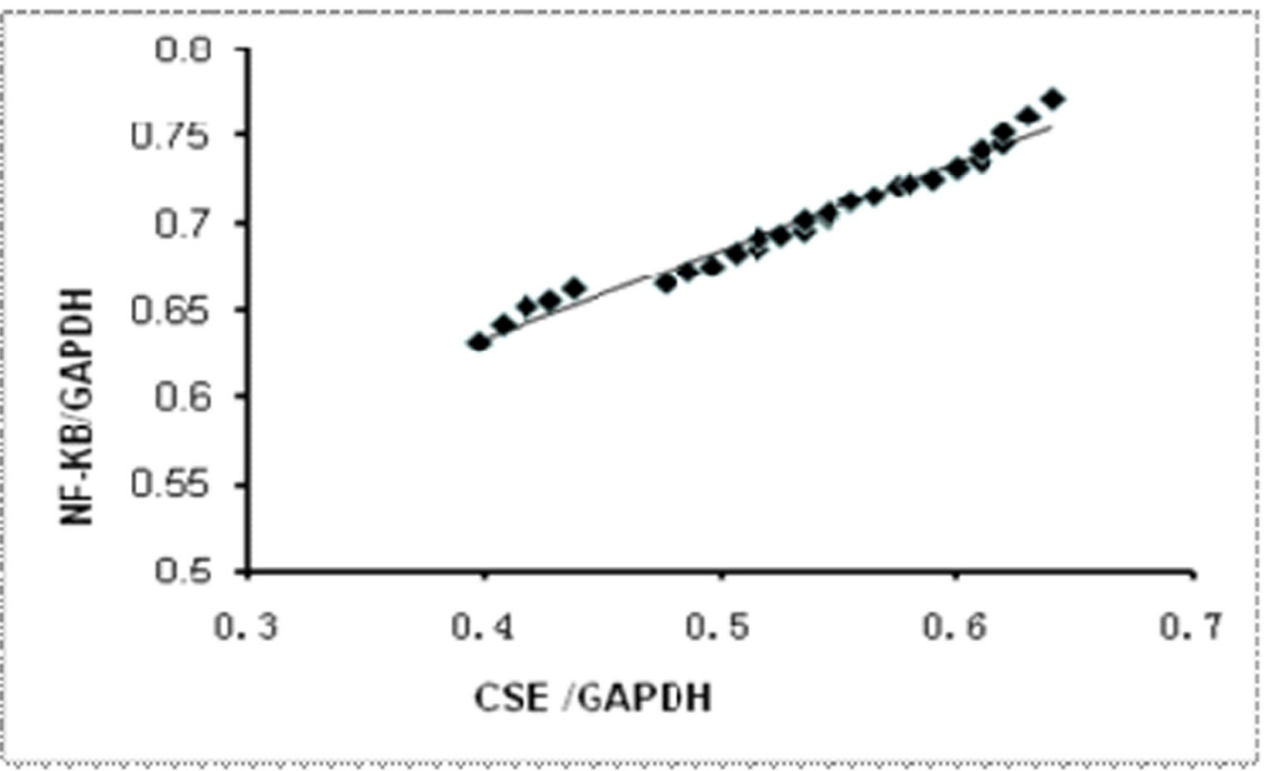

乘

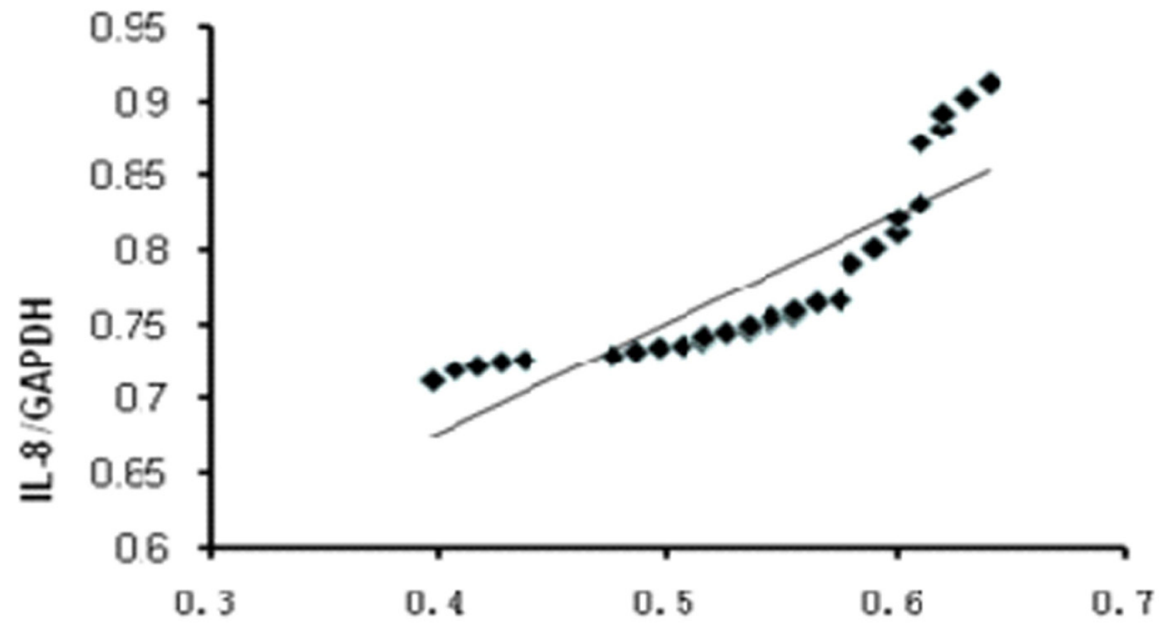

CSE /GAPDH

Fig. 4

\section{Discussion}

Hydrogen sulfide $\left(\mathrm{H}_{2} \mathrm{~S}\right)$ can protect the damage of gastric mucosa through the inhibition of inflammation factors, chemotactic cytokines, and intercellularadhesion molecules. Additionally, hydrogen sulfide $\left(\mathrm{H}_{2} \mathrm{~S}\right)$ can inhibit the production of nitrite, reactive oxygen species, and increase the blood flow in gastric mucosa. Through the above mechanisms, hydrogen sulfide $\left(\mathrm{H}_{2} \mathrm{~S}\right)$ has been demonstrated to exhibit protective role in damage of gastric mucosa induced by NSAIDs, acetate, ethanol 9-13. CBS and CSE are two key enzymes involved in the synthesis of $\mathrm{H}_{2} \mathrm{~S}$, and the activity of these two enzymes 
can reflect the level of $\mathrm{H}_{2} \mathrm{~S}$. These two enzymes are expressed in different part in gastrointestinal tract. CSE is mainly expressed in gastric mucosa ${ }^{10}$. Therefore, the present study focused on the expression of CSE.

$\mathrm{NF}-x \mathrm{~B}$ has been found in almost all animal cell types, and is involved in cellular responses to stimuli such as stress, cytokines, free radicals, and ultraviolet irradiation. $\mathrm{NF}-x \mathrm{~B}$ activation can significantly induce the expression of many cytokines, including IL-1, IL- 6 , and IL- $8{ }^{14}$. The infection of H.pylori results in the infiltration of numerous inflammation cells. Additionally, previous literatures have shown that H.pylori adhered to the surface of gastric mucosa and resulted in the secretion of antigens which damage the integrity of epidermal cells located in stomach. And then, the cell function will changed, including the activation of IL- 8 gene ${ }^{15}$. In the present study, we found the mRNA level of NF- $x \mathrm{~B}$ and IL-8 was higher in gastric ulcer patients, especially in patients with H.pylori-positive gastric ulcer, which was similar with previous studies ${ }^{15}$.

As far as we know, the present study is the first study to correlate the activity of CSE and the expression of NF- $x \mathrm{~B}$ and IL-8 which are two typical biomarkers to represent the severity of gastric ulcer. The results showed the positive correlation between CSE mRNA and the mRNA of NF-xB and IL- 8 in patients with gastric ulcer. The further analysis showed the higher expression of CSE, NF- $x \mathrm{~B}$ and IL-8 in H.pylori-positive gastric ulcer than H.pylori-negative gastric ulcer. The significant correlation between CSE and NF- $x \mathrm{~B}$ and IL-8 was also detected for H.pylori-positive gastric ulcer. All these results obtained in the present study will be helpful for the development of efficient drugs towards gastric ulcer.

\section{References}

1. Malfertheiner P. The intriguing relationship of Helicobacter pylori infection and acid secretion in peptic ulcer disease and gastric cancer. Dig. Dis. 2011;29(5):459-464.

2. Huang J, O’Toole PW, Doig P, Trust TJ. Stimulation of interleukin-8 production in epithelial cell lines by Helicobacter pylori. Infect. Immun. 1995; 63(5):17321738 .

3. Harris PR, Mobley HL, Perez-Perez GI, Blaser MJ, Smith PD. Helicobacter pylori urease is a potent stimulus of mononuclear phagocyte activation and inflammatory cytokine production. Gastroenterology 1996;111(2):419-425.
4. Peek RM, Miller GG, Tham KT, et al. Heightened inflammatory response and cytokine expression in vivo to cagA + Helicobacter pylori strains. Lab. Invest. 1995;73(6):760-770.

5. Yamaoka Y, Kita M, Kodama T, Sawai N, Imanishi J. Helicobacter pylori cagA gene and expression of cytokine messenger RNA in gastric mucosa. Gastroenterology 1996;110(6):1744-1752.

6. Linden DR. Hydrogen sulfide signaling in the gastrointestinal tract. Antioxid. Redox Signal. 2013; DOI: $10.1089 /$ ars.2013.5312.

7. Pan H, Chen D, Liu B, Xie X, Zhang J, Yang G. Effects of sodium hydrosulfide on intestinal mucosal injury in a rat model of cardiac arrest and cardiopulmonary resuscitation. Life Sci. 2013; doi: 10.1016/j.lfs.2013.05.012.

8. Fang ZZ, Nian Y, Li W, Wu JJ, Ge GB, Dong PP, Zhang YY, Qiu MH, Liu L, Yang L. Cycloartane triterpenoids from Cimicifuga yunnanensis induce apoptosis of breast cancer cells (MCF7) via p53-dependent mitochondrial signaling pathway. Phytother. Res. 2011; 25(1):17-24.

9. Wallace JL, Dicay M, McKnight W, Martin GR. Hydrogen sulfide enhances ulcer healing in rats. FASEB J. 2007; 21(14):4070-4076.

10. Fiorucci S, Antonelli E, Distrutti E, et al. Inhibition of hydrogen sulfide generation contributes to gastric injury caused by anti-inflammatory nonsteroidal drugs. Gastroenterology 2005;129(4):1210-1224.

11. Zanardo RC, Brancaleone V, Distrutti E, Fiorucci S, Cirino G, Wallace JL. Hydrogen sulfide is an endogenous modulator of leukocyte-mediated inflammation. FASEB J. 2006;20(12):2118-2120.

12. Yonezawa D, Sekiguchi F, Miyamoto M, Taniguchi E, Honjo M, Masuko T, et al. A protective role of hydrogen sulfide against oxidative stress in rat gastric mucosal epithelium. Toxicology 2007; 241(1-2):11-18.

13. Lou LX, Geng B, Du JB, Tang CS. Hydrogen sulphide-induced hypothermia attenuates stress-related ulceration in rats. Clin. Exp. Pharmacol. Physiol. 2008; 35(2):223-228.

14. Yang BC, Yang ZH, Pan XJ, Xiao FJ, Liu XY, Zhu MX, Xie JP. Crotonaldehyde-exposed macrophages induce IL-8 release from airway epithelial cells through NF- $x$ B and AP-1 pathways. Toxicol. Lett. 2013; 219(1): 26-34.

15. Isomoto H, Mizuta Y, Miyazaki M, et al. Implication of NF-kappa B in Helicobacter pylori-associated gastritis. Am. J. Gastroenterol. 2000; 95(10): 27682776. 